\title{
Incidence and Cognitive Decline of Alzheimer's Disease and Other Dementia by Apolipoprotein $\varepsilon 4$ Allele Presence: A Community-Based Cohort Study in Korean Elderly
}

\author{
So Young Yoo ${ }^{1 *}$, Alexander Han ${ }^{2 *}$, Soowon Park ${ }^{3}$, and Jun-Young Lee ${ }^{1,4 凶}$ \\ 'Department of Psychiatry, SMG-SNU Boramae Medical Center, Seoul, Republic of Korea \\ 2Department of BioSciences \& Department of Statistics, Rice University, Houston, TX, USA \\ ${ }^{3}$ Division of Teacher Education, College of General Education for Truth, Sincerity and Love, Kyonggi University, Suwon, Republic of Korea \\ ${ }^{4}$ Department of Psychiatry, Seoul National University College of Medicine, Seoul, Republic of Korea
}

\begin{abstract}
Objective This study aimed to investigate the role of apolipoprotein E (APOE) $\varepsilon 4$ allele to the incidence of dementia and cognitive decline in a cohort of a Korean community.

Methods From a community-based dementia-free cohort, 357 participants were genotyped. Participants underwent 2 cognitive assessments separated by a hiatus between 6 to 7 years and were diagnosed as healthy control $(n=297)$, Alzheimer's disease (AD) ( $n=44)$, and other dementia $(n=16)$ at the second assessment. Incidence risk and onset age of disease according to APOE $\varepsilon 4$ presence were analyzed in $\mathrm{AD}$ and other dementia. Differences in cognitive decline rate depending on APOE $\varepsilon 4$ were also examined across all groups.

Results The relative risks and onset age of dementia were not different by the presence of the APOE $\varepsilon 4$ allele. Cognitive decline was more prominent in the presence of APOE $\varepsilon 4$ allele (score change $=7.4$ ) than non-presence (score change $=3.1$ ), and this interaction was significant only in the $\mathrm{AD}$ group $(\mathrm{F}=10.51, \mathrm{p}=0.003)$.

Conclusion The APOE $\varepsilon 4$ alleles can be a critical factor in predicting cognitive change for AD in the Korean community population but not in predicting $\mathrm{AD}$ incidence. This finding suggest that clinicians consider the presence of APOE $\varepsilon 4$ allele examining patients with rapid declining dementia.

Psychiatry Investig 2022;19(3):190-196
\end{abstract}

Keywords Apolipoprotein E; Cognitive decline; Alzheimer's disease; Community.

\section{INTRODUCTION}

The apolipoprotein E (APOE) $\varepsilon 4$ allele is one of established risk factors for Alzheimer's disease $(\mathrm{AD})^{1,2}$ and other demen$\mathrm{tia}^{3}$ and also associated with cognitive function. However, the prevalence of $\varepsilon 4$ allele allele among $\mathrm{AD}$ patients vary by region and ethnicity. ${ }^{4}$

APOE $\varepsilon 4$ is also associated with an earlier age of disease onset from about 85 years without and $\varepsilon 4,75$ years with one,

Received: November 7, 2021 Revised: November 16, 2021

Accepted: November 24, 2021

$\triangle$ Correspondence: Jun-Young Lee, MD, PhD

Department of Psychiatry, Seoul National University College of Medicine \& SMG-SNU Boramae Medical Center, 20 Boramae-ro 5-gil, Dongjak-gu, Seoul 07061, Republic of Korea

Tel: +82-2-870-2462, Fax: +82-2-6280-6099, E-mail: benji@snu.ac.kr

*These authors contributed equally to this work.

(c) This is an Open Access article distributed under the terms of the Creative Commons Attribution Non-Commercial License (https://creativecommons.org/licenses/bync/4.0) which permits unrestricted non-commercial use, distribution, and reproduction in any medium, provided the original work is properly cited. and 68 years with two $\varepsilon 4$ allele even though this occurrence was not as pronounced in the male population., ${ }^{1,5}$ The association between $\varepsilon 4$ allele and $\mathrm{AD}$ prevalence is also reported in Korea. ${ }^{6}$ This relation was also observed with $\mathrm{AD}$ patients older than 100 years. ${ }^{7}$

Besides developing AD, the correlation of APOE $\varepsilon 4$ with the rate of cognitive impairment, deterioration of function, and premature death have been reported in many studies. ${ }^{8-10}$ Education and sex among the factors impacting on faster cognitive decline are considered to be associated with carriage of the APOE $\varepsilon 4$ allele although the results are mixed still. ${ }^{11-13}$ Ethoregional differences were observed also in the relationship between education and cognitive decline. ${ }^{14-16}$

We aimed to investigate the effect of the APOE $\varepsilon 4$ allele as longitudinal and lifetime risk of $\mathrm{AD}$ or other dementia and to investigate the relationship between education, sex and cognitive decline according to the APOE $\varepsilon 4$ allele in risk across the Korean-community population. 


\section{METHODS}

The study procedures were conducted in accordance with the Declaration of Helsinki and were approved by the Seoul National University Hospital Institutional Review Board, Seoul, Republic of Korea (IRB No. 0306-104-001). All participants received detailed information regarding the study aims and procedures. Written informed consent was obtained from all participants.

\section{Participants}

1,037 individuals who were legal residents of Yonchon Country and aged 65 years or older participated in the Korean Yonchon Survey (KYS) from December 1996 December 1996 through August 1997 (1st wave). Yonchon is an archetypical Korean rural agricultural county with a population of approximately 58,873 (female 26,748 [48.8\%]) in 1996 (Statistical year book, 1996, Yonchon Gun). Random multistage cluster sampling was performed considering the population structure. Its methods and design are accurately illustrated in the KYS prevalence study. ${ }^{17}$ Information was garnered on demographic variables and risk factors (age, sex, education, and literacy) during the screen phase through a semi-structured interview. Throughout the second phase, the diagnostic interviews were conducted on populations at risk and thus, a total of 370 subjects underwent phase 2 clinical evaluation, and this was conducted from January 1996 to August 1997.

A follow-up survey was conducted in 2000 and 2003 (2nd wave) for the incidence study. Total 357 individuals were included in this study for the population at risk excluding the 69 persons diagnosed with dementia n the initial survey. Following the consent of our subjects $(n=357)$, blood samples were extracted to conduct APOE genotyping. Qualified psychiatrists performed clinical interviews as well as physical and neurological evaluations. The DSM-III-R, a criteria advocated by the Alzheimer's Association or formerly established as the National Institute of Neurological and Communicative Disorders and Stroke and the Alzheimer's Disease and Related Disorders Association (NINCDS-ADRDA), served as the foundation for our clinical diagnosis of dementia and depressive disorder. ${ }^{18}$ Probable or possible AD diagnosis were given to individuals who satisfied the criteria. ${ }^{19}$ Subjects who satisfied the criteria recommended by the National Institute of Neurological Disorders and Stroke Association Internationale pour la Rechereche et l'Enseignement en Neuroscience $\left(\right.$ NINDS-AIREN) ${ }^{20}$ were diagnosed as having probable or possible VaD. Participants were grouped as healthy control $(\mathrm{n}=$ 297), AD ( $n=44)$, and other dementia $(n=16)$ based on the results of the second assessment.

\section{Korean Psychogeriatric Assessment Scale (PAS-K)}

The Psychogeriatric Assessment Scale (PAS) is a multi-dimensional tool for the differential diagnosis of dementia and depression. ${ }^{21}$ The Korean version of the Psychogeriatric Assessment Scale (PAS-K) has been shown to have good psychometric properties for screening for dementia and depression and have excellent validity and reliability on several parameters in Korea. ${ }^{22}$ A cut-off score of 8/9 on the PAS-K Cognitive Impairment Scale has been shown to be sensitive in identifying potential cases of dementia. The increased PAS-K scores indicate cognitive decline.

\section{Korean Dementia Rating Scale (K-DRS)}

Developed by Mattis, ${ }^{23}$ Dementia Rating Scale (DRS) is a measure of the stage of cognitive impairment in demented patients. The Korean Dementia Rating Scale (K-DRS), a Korean version of the original DRS scale, was validated by Chey et $\mathrm{al}^{24}$ The test comprises of five domains: attention, initiation and perseveration, visuospatial construction, conceptualization, and memory.

\section{APOE type analysis}

Genetic polymorphism was tested through PCR-RFLP (Polymerase Chain Reaction-Restriction Fragment Length Polymorphism). The DNA acquired from blood sample was amplified through the automatic thermal cycler (OmniGene, Hybaid Co, Middlesex, England) with the heat resistant Taq DNA polymerase (PerKinElmer, Waltham, MA, USA) and the properly biotinylated primer on the 5 ' terminus. Following the denaturization of the amplified DNA through 5 minutes of denaturing solution exposure at room temperature, the nitrocellulose strip with immobilized sequence-specific oligonucleotide (SSO) probes was submerged, and the shaking water bath (Heto-Holten, Denmark) was fixed at $45^{\circ} \mathrm{C}$ and $80 \mathrm{rpm}$ for 30 minutes to induce DNA hybridization. The color reaction in room temperature was induced using streptavidin with alkaline phosphatase markers, streptavidin of alkaline phosphatase, and substrate of alkaline phosphatase (5bromo-4-chloro-3-indolyl phosphate and nitro blue tetrazolium chloride). The APOE allele types were evaluated based on the read-out template.

The line formation for cysteine at position 112 identified $\varepsilon 3$. Line formations for cysteine at position 112 and 158 specified $\varepsilon 2$. Line formation for arginine at position 112 signified $\varepsilon 4$.

\section{Statistical analysis}

Descriptive statistics were performed for APOE $\varepsilon 4$ presence. Cox regression was conducted to analyze $\mathrm{AD}$ risk factor with APOE $\varepsilon 4$ presence set as the independent variable and the onset age fixed as the observation period. A paired t test was 
employed to assess the mean difference between test values by dementia onset age. The interaction of APOE $\varepsilon 4$ presence between groups (dementia, sex and education) and cognitive decline was analyzed through the General Linear Model Repeated Measures ANOVA. Statistical analyses were conducted using IBM SPSS Statistics for Windows, Version 21.0 (IBM Corp., Armonk, NY, USA). Statistical significance was based on 2 -sided design-based tests evaluated at 0.05 significance level.

\section{RESULTS}

\section{Demographic characteristics}

At baseline, descriptive summaries of the study sample present means and standard deviations for continuous variables and frequencies for categorical variables (Table 1). 54.6\% of the participants were women. The mean age and cognitive score in the initial wave were 71.6 years and 4.3, respectively. Age, education level, and cognitive score displayed statistically insignificant correlations with APOE $\varepsilon 4$ presence. APOE $\varepsilon 4$ allele frequency was $15.4 \%$ from the sample population, aligning with the worldwide average of $13.7 \% .^{25}$ The APOE4 allele frequencies for $\mathrm{AD}$ and healthy control groups were $18.2 \%$ and $14.8 \%$, respectively.

\section{Dementia risk by $\mathrm{APOE} \varepsilon 4$ allele}

Cox regression was performed to investigate the relation- ship between dementia onset and APOE $\varepsilon 4$. The age, level of education, and sex of the non-dementia subjects from the 1st wave were corrected for covariates, the APOE variant was fixed as the independent variable, and the observation period was defined as onset age. While the presence of an APOE $\varepsilon 4$ allele did not influence other dementia risks (hazard ratio, $\operatorname{Exp}(B)=0.746)$, the $\mathrm{AD}$ risks augmented by $1.05(0.48-2.26)$ folds. However, this was statistically insignificant $(\mathrm{p}=0.906)$. The APOE $\varepsilon 4$ carrier did not show statistically significant increases in both the $\mathrm{AD}$ and other dementia groups.

\section{Dementia onset ages by APOE $\varepsilon 4$ allele}

The mean ages for APOE $\varepsilon 4$ carriers and non-carriers were 71.4 and 71.6, respectively, suggesting that the difference between the two groups was not significant $(\mathrm{p}=0.837)$. The mean $\mathrm{AD}$ onset ages for APOE $\varepsilon 4$ carriers and non-carriers were 78.5 and $79.2(\mathrm{t}=0.274, \mathrm{p}=0.785)$. For other dementia, the mean onset ages for APOE $\varepsilon 4$ carriers and non-carriers were 80.3 and $76.1(\mathrm{t}=1.554, \mathrm{p}=0.143)$.

\section{Relationship between APOE $\varepsilon 4$ allele and cognitive decline rate across all participants}

Our cohort investigation suggests that APOE $\varepsilon 4$ is not correlated with $\mathrm{AD}$, indicating that the allele may not be a pathological factor for the Korean demographic ( $\mathrm{p}=0.587)$. However, APOE $\varepsilon 4$ under AD displays statistical significance in accelerated $\mathrm{AD}$ progression through the augmented cognitive

Table 1. Baseline descriptive summary according to APOE $\varepsilon 4$ presence

\begin{tabular}{lccccc}
\hline & $\varepsilon 4-(\mathrm{N}=302)$ & $\varepsilon 4+(\mathrm{N}=55)$ & t or $\chi^{2}$ & $\mathrm{p}$ & Total $(\mathrm{N}=357)$ \\
\hline 1st wave age $(\mathrm{yr})$ & $71.6(5.1)^{*}$ & $71.4(5.5)$ & 0.206 & 0.837 & $71.6(5.2)$ \\
Mean education $(\mathrm{yr})$ & $2.4(3.5)^{*}$ & $3.2(4.2)$ & 1.415 & 0.158 & $2.5(3.6)$ \\
Sex, women & $171(56.6)^{\dagger}$ & $24(43.6)$ & 3.166 & 0.075 & $195(54.6)$ \\
1st PAS-K cognitive scores & $4.3(3.3)^{*}$ & $3.9(3.5)$ & 0.897 & 0.370 & $4.3(3.3)$ \\
Normal cogniton & $253(85.2)^{\dagger}$ & $44(14.8)$ & 0.477 & 0.788 & $55(15.4)$ \\
Dementia & $36(81.8)^{\dagger}$ & $8(18.2)$ & 0.477 & 0.788 & $55(15.4)$ \\
\hline
\end{tabular}

The meaning of increased PAS scores presents cognitive decline. * mean (standard deviation); ${ }^{\dagger}$ (\% frequency). $\varepsilon 4-$, APOE $\varepsilon 4$ non-carrier; $\varepsilon 4+$, APOE $\varepsilon 4$ carrier; APOE, apolipoprotein E; PAS, Psychogeriatric Assessment Scale
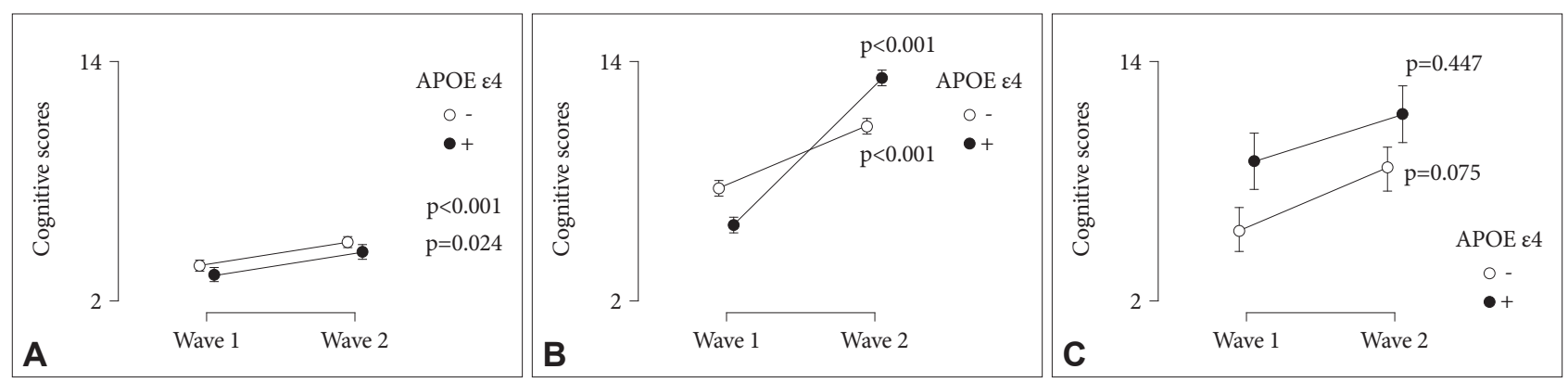

Figure 1. Cognitive score changes depending on the presence of APOE $\varepsilon 4$ in (A) healthy control, (B) Alzheimer's disease, (C) Other dementia. APOE, apolipoprotein E. 
impairment score (Figure 1). For the $\mathrm{AD}$ group, the interaction between APOE $\varepsilon 4$ carriers and $\varepsilon 4$ non-carriers was significant $\left(\mathrm{F}=10.51, \mathrm{p}=0.003, \eta^{2}=0.221\right)$ and the main effect of time was also significant $\left(\mathrm{F}=63.68, \mathrm{p}<0.001, \eta^{2}=0.633\right)$. The mean cognitive impairment value for APOE $\varepsilon 4$ carriers increased by 7.4 from 5.8 (1st wave) to 13.2 ( 2 nd wave) ( $<<0.001$ ) and by contrast, non-carriers experienced a 3.1 increase from 7.6 (1st wave) to 10.7 ( 2 nd wave) $(\mathrm{p}<0.001)$.

In the other dementia group, the interaction between APOE $\varepsilon 4$ carriers and $\varepsilon 4$ non-carriers was not significant $(\mathrm{F}=0.035$, $\left.\mathrm{p}=0.855, \eta^{2}=0.003\right)$ and the main effect of time was not also significant $\left(\mathrm{F}=2.03, \mathrm{p}=0.182, \eta^{2}=0.156\right)$.

\section{Sex and APOE $\varepsilon 4$ on cognitive decline rate}

For female sex group $(n=195)$, the cognitive score changes between APOE $\varepsilon 4$ carriers and non-carriers was significantly different $\left(F=5.919, p=0.016, \eta^{2}=0.007\right)$, and the main effect of time was also statistically significant $\left(\mathrm{F}=25.291, \mathrm{p}<0.001, \eta^{2}=\right.$ 0.029). The mean cognitive impairment value for APOE $\varepsilon 4$ carriers increased by 3.4 from the 1 st to 2 nd wave ( $<<0.001)$. Non-carriers demonstrated a decline of 1.4 during the 7-year hiatus ( $\mathrm{p}=0.036)$ (Figure 2$)$.

In the male sex group $(n=162)$, the cognitive score changes between APOE $\varepsilon 4$ carriers and non-carriers was not different $\left(\mathrm{F}=1.537, \mathrm{p}=0.217, \eta^{2}=0.002\right)$. The main effect of time was sig- nificant $\left(\mathrm{F}=5.103, \mathrm{p}=0.025, \eta^{2}=0.007\right)$. Familial dementia history, years of formal education, and illiteracy were set as covariates for both groups.

\section{Education and APOE $\varepsilon 4$ on cognitive decline rate}

The population was grouped into no, low and high education groups based on academic completion. The subjects in the high-level group $(n=13)$ completed secondary education and beyond. Individuals in the low-level group $(n=119)$ finished primary education. Also known as "basic school," primary education when these participants underwent school was approximately 3 years in length in the rural regions such as Yonchon. Those that did not finish primary education were included in the no education group ( $\mathrm{n}=221)$.

For the no education group, the cognitive score changes between APOE $\varepsilon 4$ carriers and non-carriers were significantly different $\left(\mathrm{F}=3.908, \mathrm{p}=0.049, \eta^{2}=0.004\right)$, and the main effect of time was also statistically significant $\left(\mathrm{F}=41.039, \mathrm{p}<0.001, \eta^{2}=\right.$ 0.041 ) after adjusting for familial dementia history. As shown in the Figure $3 \mathrm{~A}$, the mean cognitive impairment value for APOE $\varepsilon 4$ carriers increased by 3.1 from the 1 st to 2 nd wave $(p<0.001)$. Non-carriers demonstrated a lower decline of 1.6 during the 7 -year hiatus ( $\mathrm{p}=0.003)$.

In the low education group, the cognitive score changes APOE $\varepsilon 4$ carriers and non-carriers was not different $(\mathrm{F}=2.475, \mathrm{p}=0.119$,
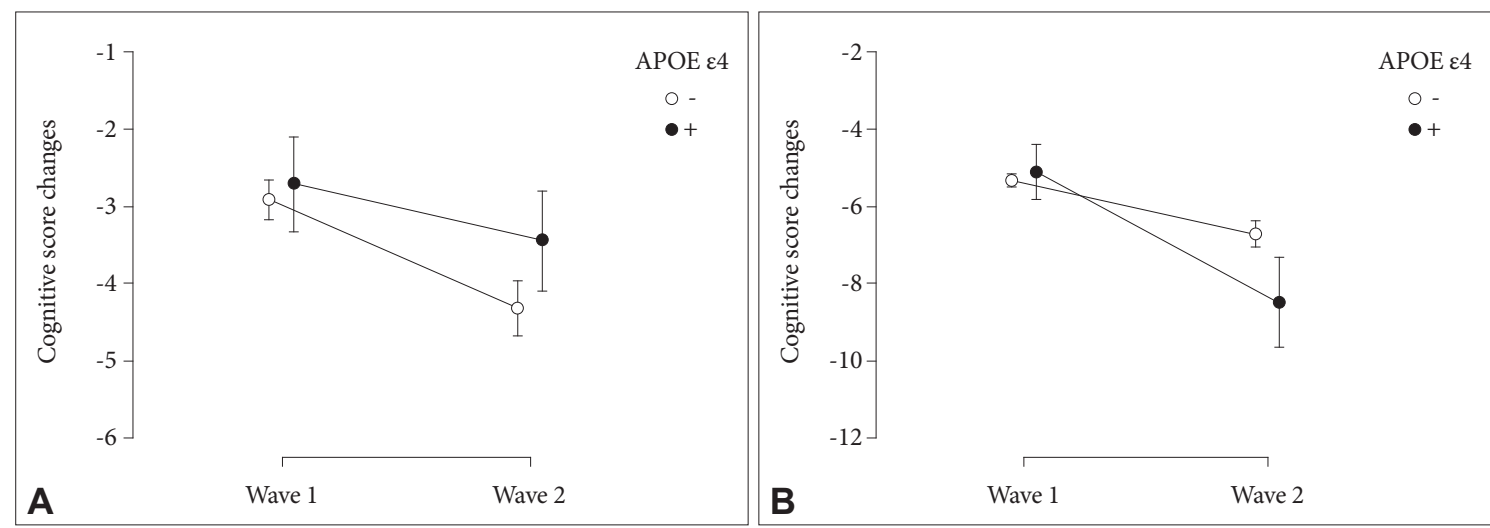

Figure 2. Cognitive score changes depending on the presence of APOE $\varepsilon 4$ in (A) male group and (B) female group. APOE, apolipoprotein E.
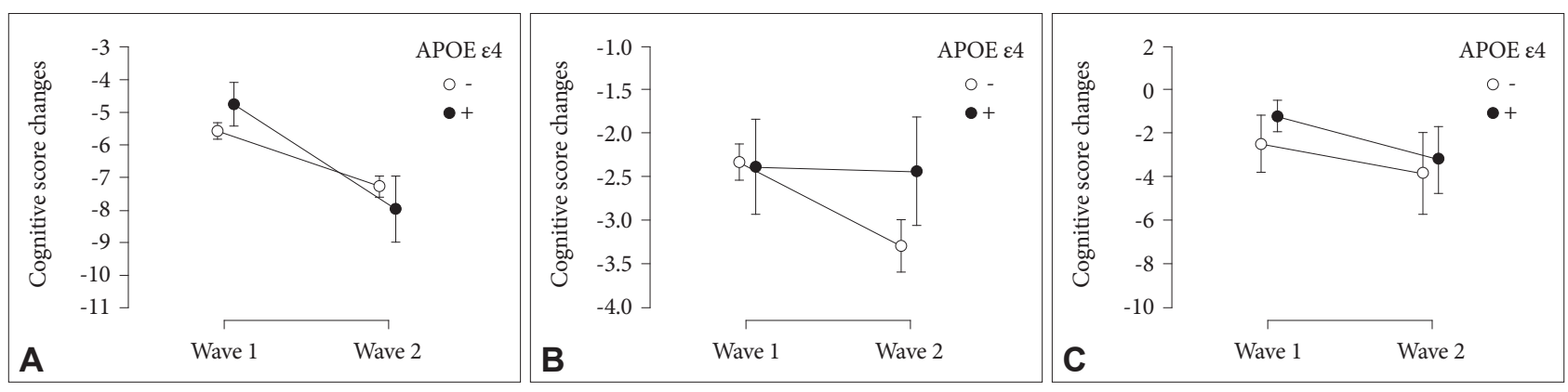

Figure 3. Cognitive score changes depending on the presence of APOE $\varepsilon 4$ in (A) no education group, (B) low education and (C) high education group. APOE, apolipoprotein $\mathrm{E}$. 
$\left.\eta^{2}=0.006\right)$. The interaction was also insignificant in the higher education group $\left(\mathrm{F}=0.185, \mathrm{p}=0.678, \eta^{2}=0.003\right)$. The main effect of time was insignificant for both the low and high education groups.

\section{DISCUSSION}

Using a community-based study of the Korean elderly, we examined the role of the APOE $\varepsilon 4$ allele to the incidence of dementia (i.e., $\mathrm{AD}$ and other dementia) and their interactions on cognitive function depending on factors of $\mathrm{AD}$ presence, sex, and education. In this study, the correlation between the onset age of dementia and the presence of the APOE $\varepsilon 4$ allele was not statistically significant. However, longitudinally collected cognitive measurements demonstrated that the APOE $\varepsilon 4$ was associated with steeper decline in $\mathrm{AD}$ groups. Cognitive decline was greater in the presence of the APOE $\varepsilon 4$ allele (score change $=7.4$ ) than its absence (score change $=3.1$ ), and this interaction was significant only in the $\mathrm{AD}$ group $(\mathrm{F}=10.51$, $\mathrm{p}=0.003$ ). In the other dementia group, the interaction between APOE $\varepsilon 4$ carriers and non-carriers was statistically insignificant. The influence of the APOE $\varepsilon 4$ allele on dementia progression is supported as astrocytes and neurons expressing the variant reduce lipid-binding capacity, augment intracellular degeneration, and decrease in phospholipid and cholesterol secretion. ${ }^{26}$ The association between the $\varepsilon 4$ variant and accelerated longitudinal cognitive decline has also been shown in community studies of both the Caucasian and Asian populations. ${ }^{27,28}$

From the aspect of relative risk of dementia (i.e., $\mathrm{AD}$ and other dementia), it was not statistically significant depending on the presence of the APOE $\varepsilon 4$ allele in present study. This finding was consistent with existing results community studies in the African, Hispanic, and Asian demographic. ${ }^{29-33}$ Previous investigations that reported the $\varepsilon 4$ variant as a significant risk factor for $\mathrm{AD}$ were largely clinical studies conducted in institutions such as nursing homes, dementia research center, and hospitals. ${ }^{1,25,34}$ This discrepancy in the significance of the APOE $\varepsilon 4$ allele can be alluded to the distinct types of studies and suggest the possibility of selection bias through the variant's role in accelerating cognitive decline. We observed that non-carriers of the $\varepsilon 4$ variant experience slower dementia progression and thus regard their cognitive change as a normal process of aging. Carriers of the allele, however, may experience significantly accelerated dementia progression and recognize their cognitive decline as a medical concern. As a result, this difference in dementia progression may culminate in clinical studies encountering increased correlation between dementia incidence and the APOE $\varepsilon 4$ allele.

This study showed APOE $\varepsilon 4$ to be sex-dependent, acceler- ating cognitive decline by a factor of more than 2 times for female carriers. Analysis of the cognitive score changes demonstrated that APOE $\varepsilon 4$ was significantly associated with sex when corrected for years of education, illiteracy, and familial dementia history. In the female group, cognitive decline was greater in APOE $\varepsilon 4$ carriers (score change $=3.4$ ) than non-carriers (score change $=1.4$ ) and this interaction was statistically significant $(\mathrm{F}=5.919, \mathrm{p}=0.016)$. By contrast, in the male group, however, interaction between APOE $\varepsilon 4$ presence and cognitive score change was not statistically significant. This finding is supported by meta-analysis that reported greater cognitive decline in female carriers than their male counterparts. ${ }^{35}$ The mechanism behind APOE $\varepsilon 4-\mathrm{AD}$ risk in women is not clear until now and Dubal and Rogine ${ }^{36}$ suggest the needs to explore the mechanisms of female vulnerability, such as whether gonadal hormones or sex chromosome mediate the APOE $\varepsilon 4$ sex difference.

While the correlation between education duration and cognitive decline was statistically insignificant, the interaction between APOE $\varepsilon 4$ and formal education experience was significant. Cognitive decline was greater in APOE $\varepsilon 4$ carriers (score change $=3.0$ ) than non-carriers (score change $=1.5$ ) only in no education group and this interaction was statistically significant $(\mathrm{F}=3.903, \mathrm{p}=0.05)$. In both the low and high education group, the difference between cognitive impairment change for APOE $\varepsilon 4$ carrier and non-carrier was insignificant. Previous studies indicate that longer education duration confers greater protection from the APOE $\varepsilon 4$ effects. ${ }^{12,37,38}$ Makkar et al. ${ }^{16}$ reported high school education was related to decreased cognitive impairment risk in Black APOE $\varepsilon 4$ carriers but in Whites, related to a significant decrease in cognitive impairment risk in non-carriers.

We can consider the unique historical context of our subjects which provides a possible explanation for the divergence between our findings and previous reports. Our sample population received education between the 1920s and early 1940s, a period characterized by the Japanese Annexation of Korea (1910-1945). During this colonial period, Japanese replaced Korean as the medium of instruction, however, the Korean language remained readily spoken among the Korean population, fostering dual language usage among students receiving colonial education. Past studies have reported that active bilingualism is a is a significant proxy for cognitive reserve and delays onset of cognitive impairment. ${ }^{39-41}$ We examined neutralized APOE $\varepsilon 4$ effects among subjects that at least completed a primary education delivered by a foreign language. This strengthens evidence for the potency of early education and suggests that dual language learning in early childhood may promote protection against the APOE $\varepsilon 4$ allele similar to the effects observed from active bilingualism on cognitive impair- 
ment. To our knowledge, this is the first study to suggest that dual language competency in early childhood can confer protection against APOE $\varepsilon 4$.

Our sample population demonstrated an insignificant difference between high and low education durations, suggesting that impact of low-quality education on cognitive decline is independent from education years beyond completion of primary school. Previous studies suggested that education factors beyond years such as community factors may influence cognitive reserve and cognitive decline $e^{42-44}$ and the relationship is curvilinear. Wilson et al.$^{45}$ reported that additional education does not contribute to further significant reductions in cognitive decline after a certain level of educational attainment and other studies have suggested that this may occur after completion of 8-9 years. ${ }^{46,47}$ Further investigation may be needed regarding the quality of education and active bilingualism on cognitive reserve.

A limitation of our study is that APOE $\varepsilon 4$ genotyping was not available for all of the participants, prompting the possibility that the frequency of the $\varepsilon 4$ variant may not be an accurate representation of the study population. In this study, there was no significant correlation between the onset age dementia and the presence of APOE $\varepsilon 4$ allele. This result may be caused by the selection bias in this study. Further study to represent whole community-based cohort would be needed.

However, our investigation has the importance to focus the association between dementia progression and the APOE $\varepsilon 4$ allele through the drug naïve and community study. This study suggests that Clinicians examining patients with rapid declining dementia should consider the presence of APOE $\varepsilon 4$ allele as well as the dementia type.

\section{Availability of Data and Material}

The datasets generated or analyzed during the study are available from the corresponding author on reasonable request.

\section{Conflicts of Interest}

The authors have no potential conflicts of interest to disclose.

\section{Author Contributions}

Conceptualization: Jun-Young Lee, Soowon Park. Data curation: Alexander Han. Formal analysis: Alexander Han, Jun-Young Lee. Funding acquisition: Jun-Young Lee. Investigation: Jun-Young Lee, Soowon Park. Mehodology: Jun-Young Lee. Project administration: Jun-Young Lee. Resources: Jun-Young Lee. Supervision: Jun-Young Lee, Soowon Park. Validation: So Young Yoo, Alexander Han. Visualization: Alexander Han. Writing-orginal draft: Alexander Han, So Young Yoo. Writing_review \& editing: Jun-Young Lee, Soowon Park.

\section{ORCID iDs}

So Young Yoo Alexander Han Soowon Park Jun-Young Lee
https://orcid.org/0000-0001-9964-126X https://orcid.org/0000-0002-2516-2343 https://orcid.org/0000-0002-5893-3124 https://orcid.org/0000-0002-3348-940X

\section{Funding Statement}

This study was supported by grants from the Korea Research Foundation Grant (KRF-2002-041-E00150) and the Korea Health 21 R\&D Project, Ministry of Health \& Welfare, Republic of Korea (A050079).

\section{REFERENCES}

1. Corder EH, Saunders AM, Strittmatter WJ, Schmechel DE, Gaskell PC, Small GW, et al. Gene dose of apolipoprotein E type 4 allele and the risk of Alzheimer's disease in late onset families. Science 1993;261:921-923.

2. Raber J, Huang Y, Ashford JW. ApoE genotype accounts for the vast majority of AD risk and AD pathology. Neurobiol Aging 2004;25:641650 .

3. Hofman A, Ott A, Breteler MM, Bots ML, Slooter AJ, van Harskamp F, et al. Atherosclerosis, apolipoprotein E, and prevalence of dementia and Alzheimer's disease in the Rotterdam Study. Lancet 1997;349:151-154.

4. Crean S, Ward A, Mercaldi CJ, Collins JM, Cook MN, Baker NL, et al. Apolipoprotein E epsilon4 prevalence in Alzheimer's disease patients varies across global populations: a systematic literature review and meta-analysis. Dement Geriatr Cogn Disord 2011;31:20-30.

5. Myers A, Holmans P, Marshall H, Kwon J, Meyer D, Ramic D, et al. Susceptibility locus for Alzheimer's disease on chromosome 10. Science 2000;290:2304-2305.

6. Kim JM, Kim SY, Bae KY, Kim SW, Shin IS, Yang SJ, et al. Apolipoprotein e4 genotype and depressive symptoms as risk factors for dementia in an older Korean population. Psychiatry Investig 2010;7:135-140.

7. Choi YH, Kim JH, Kim DK, Kim JW, Kim DK, Lee MS, et al. Distributions of ACE and APOE polymorphisms and their relations with dementia status in Korean centenarians. J Gerontol A Biol Sci Med Sci 2003;58:227-231.

8. Albrecht MA, Szoeke C, Maruff P, Savage G, Lautenschlager NT, Ellis $\mathrm{KA}$, et al. Longitudinal cognitive decline in the AIBL cohort: the role of APOE epsilon4 status. Neuropsychologia 2015;75:411-419.

9. Fei M, Jianhua W. Apolipoprotein epsilon4-allele as a significant risk factor for conversion from mild cognitive impairment to Alzheimer's disease: a meta-analysis of prospective studies. J Mol Neurosci 2013;50: 257-263.

10. Ritchie K, Dupuy AM. The current status of apo E4 as a risk factor for Alzheimer's disease: an epidemiological perspective. Int J Geriatr Psychiatry 1999;14:695-700.

11. Duara R, Barker WW, Lopez-Alberola R, Loewenstein DA, Grau LB, Gilchrist D, et al. Alzheimer's disease: interaction of apolipoprotein E genotype, family history of dementia, gender, education, ethnicity, and age of onset. Neurology 1996;46:1575-1579.

12. Seeman TE, Huang MH, Bretsky P, Crimmins E, Launer L, Guralnik JM. Education and APOE-e4 in longitudinal cognitive decline: MacArthur Studies of Successful Aging. J Gerontol B Psychol Sci Soc Sci 2005;60:P74-P83.

13. Vermeiren AP, Bosma H, Visser PJ, Zeegers MP, Graff C, Ewers M, et al. The association between APOE epsilon4 and Alzheimer-type dementia among memory clinic patients is confined to those with a higher education. The DESCRIPA Study. J Alzheimers Dis 2013;35:241-246.

14. Fitzpatrick AL, Kuller LH, Ives DG, Lopez OL, Jagust W, Breitner JC, et al. Incidence and prevalence of dementia in the Cardiovascular Health Study. J Am Geriatr Soc 2004;52:195-204.

15. Lopez ME, Turrero A, Delgado ML, Rodriguez-Rojo IC, Arrazola J, Barabash A, et al. APOE epsilon4 genotype and cognitive reserve effects on the cognitive functioning of healthy elders. Dement Geriatr Cogn Disord 2017;44:328-342.

16. Makkar SR, Lipnicki DM, Crawford JD, Kochan NA, Castro-Costa E, Lima-Costa MF, et al. APOE epsilon4 and the influence of sex, age, vascular risk factors, and ethnicity on cognitive decline. J Gerontol A Biol Sci Med Sci 2020;75:1863-1873.

17. Suh GH, Kim JK, Cho MJ. Community study of dementia in the older Korean rural population. Aust N Z J Psychiatry 2003;37:606-612. 
18. American Psychiatric Association. Diagnostic and Statistical Manual of Mental Disorders. Washington DC: American Psychiatric Press; 1987.

19. McKhann G, Drachman D, Folstein M, Katzman R, Price D, Stadlan EM. Clinical diagnosis of Alzheimer's disease: report of the NINCDSADRDA Work Group under the auspices of Department of Health and Human Services Task Force on Alzheimer's Disease. Neurology 1984; 34:939-944.

20. Roman GC, Tatemichi TK, Erkinjuntti T, Cummings JL, Masdeu JC, Garcia JH, et al. Vascular dementia: diagnostic criteria for research studies. Report of the NINDS-AIREN International Workshop. Neurology 1993;43:250-260.

21. Jorm AF, Mackinnon AJ, Henderson AS, Scott R, Christensen H, Korten AE, et al. The Psychogeriatric Assessment Scales: a multi-dimensional alternative to categorical diagnoses of dementia and depression in the elderly. Psychol Med 1995;25:447-460.

22. Cho MJ, Park IM, Shin YM. A validation study for the Korean version of Psychogeriatric Assessment Scale. J Korean Neuropsychiatr Assoc 2000;39:128-141.

23. Mattis S. Mental Status Examination for Organic Mental Syndrome in the Elderly Patients. In: Bellark A, Karasu TB, Editors. Geriatric Psychiatry. New York: Grune \& Stratton, 1976, p.77-121.

24. Chey J, Kim JW, Cho HY. Effects of apolipoprotein E phenotypes on the neuropsychological functions of community-dwelling elderly individuals without dementia. Neurosci Lett 2000;289:230-234.

25. Farrer LA, Cupples LA, Haines JL, Hyman B, Kukull WA, Mayeux R, et al. Effects of age, sex, and ethnicity on the association between apolipoprotein E genotype and Alzheimer disease. A meta-analysis. APOE and Alzheimer Disease Meta Analysis Consortium. JAMA 1997;278:13491356.

26. Mahley RW. Apolipoprotein E: from cardiovascular disease to neurodegenerative disorders. J Mol Med (Berl) 2016;94:739-746.

27. Carrasquillo MM, Crook JE, Pedraza O, Thomas CS, Pankratz VS, Allen $\mathrm{M}$, et al. Late-onset Alzheimer's risk variants in memory decline, incident mild cognitive impairment, and Alzheimer's disease. Neurobiol Aging 2015;36:60-67.

28. Todd M, Schneper L, Vasunilashorn SM, Notterman D, Ullman MT, Goldman N. Apolipoprotein E, cognitive function, and cognitive decline among older Taiwanese adults. PLoS One 2018;13:e0206118.

29. Gureje O, Ogunniyi A, Baiyewu O, Price B, Unverzagt FW, Evans RM, et al. APOE epsilon4 is not associated with Alzheimer's disease in elderly Nigerians. Ann Neurol 2006;59:182-185.

30. Myers RH, Schaefer EJ, Wilson PW, D’Agostino R, Ordovas JM, Espino A, et al. Apolipoprotein E epsilon4 association with dementia in a population-based study: the Framingham study. Neurology 1996;46:673677.

31. Osuntokun BO, Sahota A, Ogunniyi AO, Gureje O, Baiyewu O, Adeyinka A, et al. Lack of an association between apolipoprotein $\mathrm{E}$ epsilon 4 and Alzheimer's disease in elderly Nigerians. Ann Neurol 1995;38:463465.

32. Slooter AJ, Cruts M, Kalmijn S, Hofman A, Breteler MM, Van Broeck- hoven C, et al. Risk estimates of dementia by apolipoprotein E genotypes from a population-based incidence study: the Rotterdam Study. Arch Neurol 1998;55:964-968.

33. Tang MX, Stern Y, Marder K, Bell K, Gurland B, Lantigua R, et al. The APOE-epsilon4 allele and the risk of Alzheimer disease among African Americans, whites, and Hispanics. JAMA 1998;279:751-755.

34. Graff-Radford NR, Green RC, Go RC, Hutton ML, Edeki T, Bachman D, et al. Association between apolipoprotein E genotype and Alzheimer disease in African American subjects. Arch Neurol 2002;59:594-600.

35. Neu SC, Pa J, Kukull W, Beekly D, Kuzma A, Gangadharan P, et al. Apolipoprotein E genotype and sex risk factors for Alzheimer disease: a meta-analysis. JAMA Neurol 2017;74:1178-1189.

36. Dubal DB, Rogine C. Apolipoprotein E epsilon4 and risk factors for Alzheimer disease-let's talk about sex. JAMA Neurol 2017;74:11671168 .

37. Arenaza-Urquijo EM, Gonneaud J, Fouquet M, Perrotin A, Mezenge F, Landeau B, et al. Interaction between years of education and APOE epsilon4 status on frontal and temporal metabolism. Neurology 2015;85: 1392-1399.

38. Ishioka YL, Gondo Y, Fuku N, Inagaki H, Masui Y, Takayama M, et al. Effects of the APOE epsilon4 allele and education on cognitive function in Japanese centenarians. Age (Dordr) 2016;38:495-503.

39. Bialystok E, Craik FI, Freedman M. Bilingualism as a protection against the onset of symptoms of dementia. Neuropsychologia 2007;45:459-464.

40. Calabria M, Hernandez M, Cattaneo G, Suades A, Serra M, Juncadella $\mathrm{M}$, et al. Active bilingualism delays the onset of mild cognitive impairment. Neuropsychologia 2020;146:107528.

41. Craik FI, Bialystok E, Freedman M. Delaying the onset of Alzheimer disease: bilingualism as a form of cognitive reserve. Neurology 2010;75: 1726-1729.

42. Carvalho JO, Tommet D, Crane PK, Thomas ML, Claxton A, Habeck C, et al. Deconstructing racial differences: the effects of quality of education and cerebrovascular risk factors. J Gerontol B Psychol Sci Soc Sci 2015;70:545-556.

43. Crowe M, Clay OJ, Martin RC, Howard VJ, Wadley VG, Sawyer P, et al. Indicators of childhood quality of education in relation to cognitive function in older adulthood. J Gerontol A Biol Sci Med Sci 2013;68:198-204.

44. Mantri S, Fullard M, Gray SL, Weintraub D, Hubbard RA, Hennessy S, et al. Patterns of dementia treatment and frank prescribing errors in older adults with Parkinson disease. JAMA Neurol 2019;76:41-49.

45. Wilson RS, Hebert LE, Scherr PA, Barnes LL, Mendes de Leon CF, Evans DA. Educational attainment and cognitive decline in old age. Neurology 2009;72:460-465.

46. Lyketsos CG, Chen LS, Anthony JC. Cognitive decline in adulthood: an 11.5-year follow-up of the Baltimore Epidemiologic Catchment Area study. Am J Psychiatry 1999;156:58-65.

47. Zahodne LB, Stern Y, Manly JJ. Differing effects of education on cognitive decline in diverse elders with low versus high educational attainment. Neuropsychology 2015;29:649-657. 